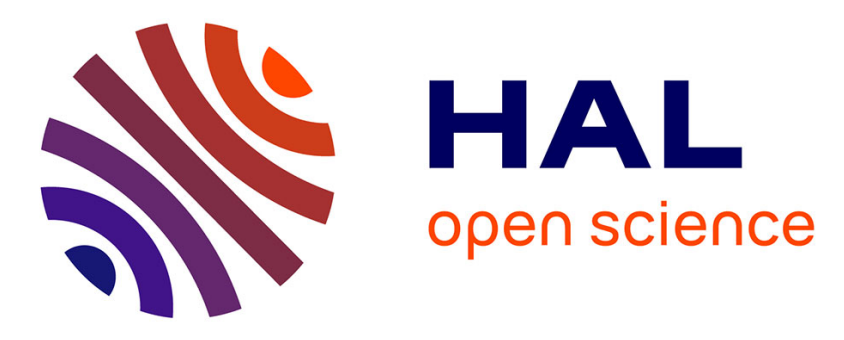

\title{
Antimicrobial cellulose nanofibril porous materials obtained by supercritical impregnation of thymol
}

Clémentine Darpentigny, Pierre R Marcoux, Mathilde Menneteau, Bastien

Michel, Florence Ricoul, Bruno Jean, Julien Bras, Guillaume Nonglaton

\section{- To cite this version:}

Clémentine Darpentigny, Pierre R Marcoux, Mathilde Menneteau, Bastien Michel, Florence Ricoul, et al.. Antimicrobial cellulose nanofibril porous materials obtained by supercritical impregnation of thymol. ACS Applied Bio Materials, 2020, 3 (5), pp.2965-2975. 10.1021/acsabm.0c00033 . hal03002985

\section{HAL Id: hal-03002985 \\ https://hal.science/hal-03002985}

Submitted on 13 Nov 2020

HAL is a multi-disciplinary open access archive for the deposit and dissemination of scientific research documents, whether they are published or not. The documents may come from teaching and research institutions in France or abroad, or from public or private research centers.
L'archive ouverte pluridisciplinaire HAL, est destinée au dépôt et à la diffusion de documents scientifiques de niveau recherche, publiés ou non, émanant des établissements d'enseignement et de recherche français ou étrangers, des laboratoires publics ou privés. 


\title{
Antimicrobial cellulose nanofibril porous materials
}

\section{obtained by supercritical impregnation of thymol.}

\author{
Clémentine DARPENTIGNY, ${ }^{\dagger, t, \S}$ Pierre R. MARCOUX, ${ }^{\S}$ Mathilde MENNETEAU,${ }^{\S}$ Bastien \\ MICHEL,${ }^{\S}$ Florence RICOUL,${ }^{\S}$ Bruno JEAN, ${ }^{\dagger}$ Julien BRAS, ${ }^{\dagger}$ and Guillaume NONGLATON ${ }^{\S}$ \\ ${ }^{\S}$ Univ. Grenoble Alpes, CEA, LETI, MINATEC Campus, F-38054 Grenoble, France \\ ${ }^{\dagger}$ Univ. Grenoble Alpes, CNRS, CERMAV, 38000 Grenoble, France \\ ${ }^{\ddagger}$ Univ. Grenoble Alpes, CNRS, Grenoble INP, LGP2, F-38000 Grenoble, France
}

\begin{abstract}
This study presents the impregnation in supercritical carbon dioxide $\left(\mathrm{scCO}_{2}\right)$ of nanocellulosebased structures with thymol as a natural antimicrobial molecule to prepare bioactive biosourced materials. First, cellulose nanofibrils (CNFs) were used to produce four types of materials (nanopapers, cryogels from water or tert-butyl alcohol suspensions and aerogels) of increasing specific surface area up to $160 \mathrm{~m}^{2} \cdot \mathrm{g}^{-1}$ thanks to the use of different processes, namely vacuum filtration, freeze-drying and supercritical drying. Secondly, these CNF-based structures were impregnated with thymol in $\mathrm{scCO}_{2}$ medium using relatively low temperature and pressure of $40^{\circ} \mathrm{C}$ and 100 bars during 1 hour. The amount of impregnated thymol in the different CNFmaterials was investigated by fluorescence spectroscopy, ${ }^{13} \mathrm{C}$ NMR analysis and gas
\end{abstract}


chromatography. All three methods consistently show that the amount of impregnated thymol increases with the specific surface area of the material. The antimicrobial activity of the impregnated CNF-based materials was then measured against three reference strains of microorganisms: the Gram-negative E. coli and Gram-positive S. epidermidis bacteria and the yeast $C$. albicans using the disk diffusion test method. The latter revealed the leaching of thymol in sufficient amount to generate antimicrobial activity against the three strains in the case of the cryogel derived form a tert-butyl alcohol suspension and the aerogel, which are the two materials exhibiting the highest specific surface areas. The proposed strategy therefore enabled us to precisely steer the amount of active molecule loading and the related antimicrobial activity by adjusting the specific surface area of the biosourced material impregnated in green supercritical conditions. These results are very promising and confirm that supercritical impregnation of active molecules onto nanocellulose 3D structures can be an interesting solution for the design of active medical devices such as wound dressings.

\section{Keywords}

Nanocellulose; Antimicrobial; Supercritical CO2; Impregnation; Thymol; Cryogel; Aerogel 


\section{INTRODUCTION}

Wound dressings have been developed in order to protect the injured skin from the environment and minimize the loss of the skin functions. ${ }^{1}$ Active principles have been incorporated into these materials in order to enhance healing, promote the distribution of growth factors and prevent microbial infection. In order to reduce the microbial burden of a wound, various antibacterial agents have been incorporated in wound dressings. ${ }^{2}$ Recently, Pérez-Recalde et al. reviewed the use of essential oils for wound dressing applications and pointed out the positive capabilities of essential oils in terms of antimicrobial and anti-inflammatory activities, biocompatibility and wound healing in animal models. ${ }^{3}$ Among the various essential oil molecules involved in wound healing, thymol is often mentioned. ${ }^{4}$ This compound is a monoterpene phenol found in essential oils and abundant in Thymus vulgaris (thyme) and generally recognized as safe. ${ }^{5}$ This natural molecule has significant antibacterial and antifungal activities by increasing the membrane ion permeability leading to cell death ${ }^{6-8}$ and also exhibits other interesting properties such as anti-inflammatory, antioxidant, scar healing and even anticancer functions. $^{9,10}$

Numerous studies have been published on the development of polymeric materials, and in particular biobased polymers, with antimicrobial activity for different fields of applications such as medicine, pharmacy, food, aeronautics, etc. These works, reviewed recently by Chen, MuñozBonilla and Fernández-García, demonstrate the interest of polymers in particular because of their low toxicity. ${ }^{11-13}$ Natural and biocompatible polymers are gaining interest for the development of wound dressings. ${ }^{14-16}$ In this framework, nanocellulose are a class of bio-based, biocompatible and bio-degradable particles that are widely investigated for biomedical and wound healing applications. ${ }^{17,18}$ Nanoscale cellulose can be extracted from the biomass in the form of cellulose 
nanocrystals (CNCs) and cellulose nanofibrils (CNFs). More specifically, CNFs are semicrystalline, long and entangled fibers obtained after mechanical disintegration, combined to chemical or enzymatic pretreatment. These particles derived from a naturally abundant and renewable source exhibit interesting properties, such as low toxicity, lightweight, high specific surface area and good mechanical properties, in addition to industrial scale production. ${ }^{19,20}$ Nanocellulose-based 3D materials with different architectures can be obtained by playing on the drying process. For example, foam-like materials showing high porosity and high specific surface area have been prepared by freeze-drying or supercritical drying of nanocellulose suspensions. ${ }^{21-}$ ${ }^{23}$ Alternatively, dense structures such as films and nanopapers can be prepared by solvent casting or vacuum filtration. ${ }^{24,25}$

The promising combination of essential oil with biopolymers in the wound healing process was discussed in the aforementioned article. ${ }^{3}$ Chitosan films incorporated with thyme essential oil exhibited antioxidant and antibacterial activity against four bacterial strains. ${ }^{26}$ Cellulose hydrogels of bacterial origin loaded with thymol exhibited antimicrobial activity and promoted rapid wound closure of third degree burn wounds. ${ }^{27}$ Essential oil molecules are often volatile with a very low solubility in aqueous media. While their extraction can be performed in toxic organic solvents, supercritical carbon dioxide $\left(\mathrm{scCO}_{2}\right)$ extraction of essential oils is now widely used and studied as an environmentally-friendly extraction technology for high-quality oils. ${ }^{28,29}$ Beside being a good and suitable solvent for apolar molecules this fluid reaches its supercritical state at low critical temperature and pressure of $31.1^{\circ} \mathrm{C}$ and 73.8 bars, respectively. The supercritical state allows efficient mass transport and high diffusivity in organic materials. Thymol and other essential oil molecules have been impregnated into various matrices using $\mathrm{scCO}_{2} \cdot{ }^{30,31}$ The solubility of thymol was investigated by Milovanovic et al. at different pressures and temperatures. Consequently, they performed the impregnation on cotton gauzes at $35^{\circ} \mathrm{C}$ and 155 
bars which conferred antimicrobial properties to the material. ${ }^{32}$ Very recently, the same team performed the impregnation of thymol in polylactic acid and poly(lactic-co-glycolic acid) foams and observed a controlled release of thymol over three weeks. ${ }^{33}$ Homogeneous impregnations have been reported and the process is often referred to as easy and does not require any additional processing step of solvent removal compared to impregnations performed in conventional solvents. Cellulose acetate films ${ }^{34}$ and poly(vinyl alcohol)-cellulose nanocrystals membranes ${ }^{35}$ were impregnated in supercritical carbon dioxide with thymol to prevent biofilm formation and develop active food packaging. However, up to our knowledge, there is no literature about pure cellulose nanofibril porous structures impregnated in supercritical carbon dioxide. Supercritical carbon dioxide presents several advantages compared to traditional organic solvents: an enhanced solubility in $\mathrm{scCO}_{2}$, favorable transport properties (thereby high mass transfer rates, especially in porous media), and $\mathrm{scCO}_{2}$ features both the high density of liquids and the low viscosity and very low surface tension of gases. Very low surface tension is crucial when wetting of nanoporous structures is targeted.

In this context, CNF structures have been prepared and impregnated with thymol in supercritical carbon dioxide. In order to investigate the influence of the structure on the efficiency of supercritical impregnation with essential oils, CNF structures with different porosities and specific surface areas were impregnated and compared. Their potential as active materials for wound dressing applications was evaluated by investigating their antimicrobial activity and cytotoxicity.

\section{EXPERIMENTAL SECTION}

\section{Chemicals and materials}


Thymol (CAS: 89-83-8, $\geq 98.5 \%$ ), hydrogen peroxide solution (CAS: 7722-84-1, 30 wt./wt. \% in $\mathrm{H}_{2} \mathrm{O}$ containing stabilizer) and methanol (CAS: 67-56-1, >99.9\%, for HPLC) were purchased from Sigma-Aldrich. Phosphate buffered saline (PBS) (10X) was purchased from Fisher Scientific and diluted 10 times before use. Ethanol absolute anhydrous (64-17-5, RSE for electronic use) was purchased from Carlo Erba reagents. Tert-butyl alcohol ( $t \mathrm{BuOH})(\geq 99.0 \%$, CAS number: 75-65-0) was purchased from Fisher Scientific and used without any further purification. Liquid $\mathrm{CO}_{2}$ (CAS: 124-38-9) was supplied by Air Liquide. Mueller-Hinton broth prepared from powder, Mueller-Hinton agar plates and pharmacopoeia diluent $(\mathrm{NaCl}$ peptone broth at $\mathrm{pH}$ 7) were purchased from VWR Chemicals. The cell proliferation reagent WST-1 for the spectrophotometric quantification of cell proliferation and viability was supplied by Roche.

A suspension of cellulose nanofibrils (Exilva P) at 2 wt. \% solid content with a hemicellulose content of $2.8 \%$.was provided by Borregaard. The suspension was diluted to a $1 \%$ solid content with an Ultra Turrax IKA T25 stirrer at 8000 rpm during 5 minutes.

The microorganism strains Staphylococcus epidermidis ATCC 14990, Escherichia coli ATCC 25922 and Candida albicans ATCC 14053 were supplied as KWIK-STIK lyophilized strains (Microbiologics).

\section{CNF-based materials preparation}

A handsheet former (Rapid Kothen, ISO 5269-2) was used for the production of CNF nanopapers (NP). A suspension of $400 \mathrm{~mL}$ of CNFs at $0.5 \mathrm{wt} . \%(2 \mathrm{~g}$ dry) in deionized water was filtered through a $1 \mu \mathrm{m}$ nylon sieve at -600 mbar during approximately 5 min, until complete water filtration. The wet sheet was then dried at $85^{\circ} \mathrm{C}$ under vacuum during 20 minutes, between two nylon sieves and two cardboard sheets to prevent adhesion.

$\mathrm{CNF}$ solvent exchange to $t \mathrm{BuOH}$ was performed by centrifugation-dispersion cycles. A suspension of CNFs was centrifuged at $11200 \mathrm{rpm}$ during 30 minutes at room temperature. The 
supernatant was discarded and the pellet redispersed in $t \mathrm{BuOH}$ at $30^{\circ} \mathrm{C}$. Four centrifugationdispersion cycles were performed and the last dispersion was performed in $t \mathrm{BuOH} / \mathrm{H}_{2} \mathrm{O}$ 80:20 (vol/vol) mixture.

Freeze-drying of the CNF cryogels was performed in a Cryotec ${ }^{\circledR}$ shelves lyophilizer from a suspension in water to yield the cryogels called $\mathrm{GCw}$ or from a suspension in $t \mathrm{BuOH}$ to yield the $\mathrm{CGtBuOH}$ cryogel. The CNF suspension was poured into cylindrical molds. Directional freezing occurred as the suspension was in direct contact with the lyophilizer shelves at $-50^{\circ} \mathrm{C}$ at atmospheric pressure for 2 hours. An increase of temperature from $-50^{\circ} \mathrm{C}$ to $20^{\circ} \mathrm{C}$ in 24 hours at 0.1 mbar was applied. Then the temperature was maintained and pressure decreased to $0.01 \mathrm{mbar}$ during 30 minutes. The recovered cryogels were stored in a clean room environment at relative humidity varying from 45 to $55 \%$.

Aerogels (AG) were obtained by supercritical drying employing a supercritical SFD-200 equipment (SEPAREX, 31Degrees, France) and a procedure previously described. ${ }^{36}$ The CNF suspension was placed in PTFE molds sizing $1 \mathrm{~cm}$ in height and $1 \mathrm{~cm}$ in diameter and immersed during 30 minutes in aqueous ethanol solutions of increasing ethanol percentage $(25 \%, 50 \%, 75$ $\%, 100 \%)$. The last immersion in absolute ethanol was repeated twice during 24 hours. The molds containing the suspension in ethanol were then placed in the supercritical equipment at a temperature of $18{ }^{\circ} \mathrm{C}$ and the pressure was increased to 100 bars at a rate of 20 bars. $\min ^{-1}$. After three successive baths in liquid $\mathrm{CO}_{2}$, the temperature was increased to $45^{\circ} \mathrm{C}$ and maintained during 1 hour. Finally, the pressure was decreased to atmospheric pressure at a rate of 8 bars.min ${ }^{-}$

${ }^{1}$. The obtained aerogels were stored in a clean room environment at relative humidity varying from 45 to $55 \%$.

\section{Supercritical impregnation of thymol}


The impregnation was performed with the SFD-200 equipment. The CNF materials were placed on an aluminum holder and $200 \mathrm{mg}$ of thymol in the form of powder were placed inside another aluminum container. The temperature was increased to $40^{\circ} \mathrm{C}$ and the pressure to 100 bars at a rate of 20 bars.min ${ }^{-1}$. A dynamic step of 1 min under a $\mathrm{CO}_{2}$ flow of $50 \mathrm{~g} \cdot \mathrm{min}^{-1}$ was performed for system equilibration. The pressure and temperature were maintained during 1 hour, during which the thymol dissolved and impregnated the materials, which were then washed during 5 min under a $\mathrm{CO}_{2}$ flow of $50 \mathrm{~g} \cdot \mathrm{min}^{-1}$. The pressure was finally decreased at a rate of 8 bars.min ${ }^{-1}$ till atmospheric pressure and the materials were recovered and placed in sealed containers at $5^{\circ} \mathrm{C}$ until characterization. Characterization and impregnation were performed on the same day.

\section{Materials characterization}

\section{Electron microscopy}

The cellulose nanofibril suspension was observed with a Philips CM200 CRYO transmission electron microscope (TEM) at $80 \mathrm{kV}$. On a carbon grid, a diluted suspension was deposited and excess liquid was removed. Enhanced contrast was achieved by adding a $2 \%$ uranyl acetate aqueous solution.

A FEI Quanta 250 scanning electron microscope (SEM) equipped with a field emission gun and operating at $2 \mathrm{kV}$ was used to acquire CNF cryogels and aerogels images, after sample coating with gold/palladium ( $2 \mathrm{~nm}$ layer). CNF nanopapers images were acquired similarly with a Quanta 200 SEM.

\section{Porosity}

The density of cryogels and aerogels is calculated from the weight and volume of the sample.

The porosity, $P$, was calculated from the following equation: 
$P(\%)=\left(1-\frac{\rho}{\rho_{c}}\right) \times 100$, where $\rho$ stands for the cryogel density and $\rho_{c}$ for the cellulose density $\left(1.60 \mathrm{~g} . \mathrm{cm}^{-3}\right)$. At least 10 densities values were measured for each sample.

\section{Nitrogen adsorption}

The adsorption-desorption nitrogen isotherms were performed at $-196^{\circ} \mathrm{C}$ after degassing of around $100 \mathrm{mg}$ of sample at $105^{\circ} \mathrm{C}$ during 12 hours at a stable $1 \mu \mathrm{m} \mathrm{Hg}$ vacuum. The specific surface area was measured using a Micromeritics ASAP 2420 Surface Area and Porosity. The Brunauer, Emmett, Teller (BET) method $^{37}$ was used for the specific surface area calculations and triplicates were performed for each sample.

\section{Fluorescence}

Preliminary fluorescence analysis of thymol in solution was performed with a luminescence spectrometer LS50B from PerkinElmer. The excitation spectrum of thymol was acquired for an emission wavelength of $600 \mathrm{~nm}$ and maximum excitation wavelength were found in the $495-$ $535 \mathrm{~nm}$ range. Then the emission spectrum for an excitation wavelength of $532 \mathrm{~nm}$ was acquired and a peak between $570-660 \mathrm{~nm}$ was obtained.

The impregnated materials were analyzed with a LS Reloaded fluorescence scanner from Tecan at $532 \mathrm{~nm}$ excitation wavelength and the emission was read using a $575 \mathrm{~nm}$ filter. The cryogels and aerogels were cut in thin and homogeneous slices of $3 \mathrm{~mm}$ thickness at the center of the porous structure. A given slice was placed inside the scanner and the fluorescence was read throughout the slice. The sensitivity of the photomultiplier tube, called PMT gain, was set to 110 for each scan. At least three fluorescence intensity profiles were recorded for every slice.

\section{Solid-state nuclear magnetic resonance (SS-NMR)}

The solid-state ${ }^{13} \mathrm{C}$ NMR spectra were acquired using a Bruker Avance DSX $400 \mathrm{MHz}$ spectrometer in cross-polarization and magic angle spinning conditions (CP-MAS). The ${ }^{13} \mathrm{C}$ radio 
frequency field strength was obtained from the Hartman-Hahn conditions at $60 \mathrm{kHz}$. A spinning speed of $12000 \mathrm{~Hz}$ and operating condition of $100.6 \mathrm{MHz}$ were used. A minimum number of 10000 scans were recorded and the contact time and recycle delay were set to $2 \mathrm{~ms}$ and $2 \mathrm{~s}$, respectively. The sweep width at $29400 \mathrm{~Hz}$ and the acquisition time was set at $35 \mathrm{~ms}$. The reference spectrum of glycine was used for scaling factor correction and the spectra were normalized with cellulose $\mathrm{C} 1$ peak at around $105 \mathrm{ppm}$. The degree of crystallinity was measured from carbon 4 signal that split into two peaks, corresponding to the contribution of crystalline and amorphous parts of cellulose.

Thermo-desorption gas chromatography mass spectroscopy (TD-GC-MS)

An ATD-GC-MS equipment from Perkin-Elmer (Turbomatrix 150 and Clarus 500-560) was used. Between 10 to $15 \mathrm{mg}$ of materials were placed inside a thermo desorption glass tube (Supelco 29538). Thermo-desorption (TD) was performed by heating the tube at $180^{\circ} \mathrm{C}$ during 5 min in the ATD and inlet and outlet splits were set so that a dilution factor of 330 was obtained. Gas chromatography (GC) separation was performed with a 15 meters 5 ms column (S2B-5MS Supelco) at $100^{\circ} \mathrm{C}$ and $10 \mathrm{psi}$, with helium as carrier gas. The mass spectrometer detector was used at the end of the column. The ion source temperature was set to $200{ }^{\circ} \mathrm{C}$. Mass spectra were obtained by electronic ionization at $70 \mathrm{eV}$ from 35 to $200 \mathrm{~m} / \mathrm{z}$. The amount of thymol was deduced from the calibration with known thymol concentrations in methanol performed in the same conditions. Duplicates were performed from two different impregnation runs.

\section{Drug release test}

About 5 to $10 \mathrm{mg}$ of impregnated sample were placed in $15 \mathrm{~mL}$ of PBS solution to reach sink conditions, a dilution such that the volume of PBS is ten times higher than the volume of the saturated solution. It was incubated at $30^{\circ} \mathrm{C}$ under orbital shaking $(75 \mathrm{rpm})$. At pre-determined times, $1 \mathrm{~mL}$ of the releasing solution was removed and analyzed using a UV-visible 
spectrophotometer (Cary-300, Varian) and the absorption was recorded at wavelengths from 200 to $400 \mathrm{~nm}$, before being returned to the medium. The calibration of thymol was performed with absorbance values at $274 \mathrm{~nm}$. Duplicates were performed.

\section{In vitro properties assessment}

\section{Minimum inhibitory concentration}

The sensitivity to thymol of the three microorganisms, namely E. coli, S. epidermidis and $C$. albicans was evaluated by determining the minimum inhibitory concentration (MIC) through broth dilution tests. E. coli, S. epidermidis were cultured overnight at $37^{\circ} \mathrm{C}$ and C. albicans at $30^{\circ} \mathrm{C}$, until they reached the exponential growth phase. A series of broth tubes (Mueller-Hinton) containing thymol concentrations in the range of 1000 to $0.25 \mu \mathrm{g} / \mathrm{mL}$ (2-fold dilutions) was prepared and inoculated with a standard density $(0.5 \mathrm{McF})$ of the tested organism. The series was then incubated in a 96 -wells microplate at $37^{\circ} \mathrm{C}$ or $30^{\circ} \mathrm{C}$ during 16 hours, and the optical density of the microbial suspension was recorded at $600 \mathrm{~nm}$ every 15 minutes with an Infinite-M1000 Tecan microplate reader. After incubation, the MIC was established as the lowest concentration of thymol that prevents bacterial growth. Negative (sterile) and positive (no antibacterial agent) controls were performed. The determination of the MIC was performed in tetraplicates.

\section{Disk diffusion test}

The antimicrobial activity of the materials towards E. coli, S. epidermidis and C. albicans was evaluated using a method adapted from the Kirby-Bauer test. ${ }^{38}$ From at least three isolated colonies in exponential growth phase on an agar medium (Tryptic Soy agar), a microbial suspension was prepared so that it matched a turbidity standard of $0.5 \mathrm{McF}$. A sterile cotton swab (bioMérieux, 70610) was dipped into the standardized bacterial test suspension and used to evenly inoculate the entire surface of a Mueller-Hinton agar plate (90 mm diameter). After the agar surface has dried for about 5 minutes, the materials to be tested were placed on inoculated 
agar with sterilized forceps. The tested materials were nanopapers, cryogels and aerogels of $c a$. $10 \mathrm{~mm}$ in diameter and $5 \mathrm{~mm}$ high for the porous structures. They were incubated for 24 hours at required temperature of $37^{\circ} \mathrm{C}$ (for E. coli and S. epidermidis), or $30^{\circ} \mathrm{C}$ (for C. albicans) after which a microbial lawn has developed. The plates were photographed and the inhibition zones around the materials were measured to the nearest mm using ImageJ software. In order to present values comparable with the literature, the value of the material tested is assumed to be of $6 \mathrm{~mm}$, which is the diameter of commercial diffusion disk. The inhibition diameter, in $\mathrm{mm}$, is therefore calculated as two-times the inhibition zone added to 6. Triplicates were made and positive and negative controls were done to assay the microorganisms growth and the sterility conditions.

\section{Cytotoxicity experiments}

To assess the cytocompatibility of the materials, fibroblasts were selected as they play an important role in wound repair. NIH3T3 fibroblasts were seeded in 96 wells plates at a density of $4 \times 10^{3}$ cells per well, during 24 hours. The growth medium was removed and replaced with 200 $\mu \mathrm{L}$ growth medium added with thymol at increasing concentrations. A positive control (live) and a negative control with $10 \mathrm{mM}$ of $\mathrm{H}_{2} \mathrm{O}_{2}$ (dead) were performed. After 24 hours, the growth medium was removed and replaced with $100 \mu \mathrm{L}$ of growth medium and $10 \mu \mathrm{L}$ of WST-1 reagent. In the presence of mitochondrial succinate dehydrogenase, the reagent was reduced and formed a yellow formazan compound whose quantity is proportional to the amount of living cells. After 2 hours of incubation at $37^{\circ} \mathrm{C}$ the viability was deduced by reading the absorbance at $450 \mathrm{~nm}$ with an Infinite-M1000 TECAN microplate reader. Experiments were conducted in sextuplicates.

Two different protocols took place to evaluate the cytotoxicity of the solid materials, which were previously sterilized under UV light during $15 \mathrm{~min}$.

Direct protocol (in triplicates): NIH-3T3 fibroblasts were cultured in a 24-wells plate with a density of $9.10^{4}$ cells per well in $1 \mathrm{~mL}$ of growth medium in the presence of the sample to be 
tested. The CNF materials were presoaked in the culture medium. Negative $\left(10 \mathrm{mM}\right.$ of $\left.\mathrm{H}_{2} \mathrm{O}_{2}\right)$ and positive (growth medium) controls were conducted. The plates were incubated at $37^{\circ} \mathrm{C}$ during 24 hours, after which $100 \mu \mathrm{L}$ of WST-1 reagent was added and the viability was deduced after 2 hours of incubation through an absorbance measurement at $450 \mathrm{~nm}$ with an Infinite-M1000 TECAN microplate reader.

Indirect protocol (in triplicates): extracts were obtained by placing the materials to be tested in a separate growth medium for 24 hours at $37^{\circ} \mathrm{C}$. The cells were cultured at a density of $4.5 \times 10^{4}$ cells per well in $500 \mu \mathrm{L}$ of culture medium during 24 hours. Negative $\left(10 \mathrm{mM}\right.$ of $\left.\mathrm{H}_{2} \mathrm{O}_{2}\right)$ and positive (growth medium) controls were performed. After 24 hours incubation at $37^{\circ} \mathrm{C}$, the cells culture media was removed and replaced with the extracts solution. The $50 \mu \mathrm{L}$ of WST-1 reagent was added and the viability was deduced after 2 hours of incubation by reading the absorbance at $450 \mathrm{~nm}$ with an Infinite-M1000 TECAN microplate reader.

\section{RESULTS AND DISCUSSION}

\section{Cellulose nanofibril 2D and 3D as-prepared and impregnated structures}

The suspension of CNFs used to prepare dense and porous materials appears as a white opaque gel. Long and entangled fibrils are observed from TEM images with an average width of $25 \mathrm{~nm}$ and a length higher than $1.7 \mu \mathrm{m}$ (Supporting Information, Figure S1). Depending on the drying process used to prepare the CNF materials, very different structures were obtained. Vacuum filtration of the CNFs yielded dense 2D structures classically called nanopapers (NP). ${ }^{25}$ As described in our previous work, freeze-drying or supercritical drying yielded different types of 3D solid foams. ${ }^{36}$ Freeze-drying of the CNF suspension produced highly porous cryogels. The main morphological difference observed in SEM images between cryogels obtained prior (CGw) 
and after solvent exchange $(\mathrm{CGtBuOH})$ is the formation of dense walls in $\mathrm{CGw}$ due to the growth of ice crystals. Moreover, the photographs show that a flat, nonporous membrane is covering the structure of $\mathrm{CGw}$, while this loss of porosity is not observed for $\mathrm{CGtBuOH}$. Aerogels (AG) obtained by supercritical drying exhibit a highly fibrillary organization.

In Table 1, the preparation processes of the different structures are summarized along with their densities and specific surface areas. Nanopapers have a very high density arising from the vacuum filtration process. The two cryogels and the aerogel exhibit low densities between 10 and $24 \mathrm{mg} \cdot \mathrm{cm}^{-3}$. The variations between $\mathrm{CGw}, \mathrm{CGtBuOH}$ and $\mathrm{AG}$ can be explained by the differences in shrinkages induced by the different processes. ${ }^{36}$ The specific surface area of NP was too low to be measured using nitrogen adsorption method. A value of $25 \mathrm{~m}^{2} \cdot \mathrm{g}^{-1}$ was obtained for $\mathrm{CGw}$. Freeze-drying after solvent exchange to $t \mathrm{BuOH}$ results in an increase of the specific surface area to $97 \mathrm{~m}^{2} \cdot \mathrm{g}^{-1}$. Supercritical drying yields the highest specific surface area of $160 \mathrm{~m}^{2} \cdot \mathrm{g}^{-}$ $-1$

Table 1. Properties of density, specific surface area and pore sizes of the various CNF structures depending on their preparation process. Values extracted from reference 36.

\begin{tabular}{lllll} 
& $\mathrm{NP}$ & $\mathrm{CGw}$ & $\mathrm{CGtBuOH}$ & $\mathrm{AG}$ \\
\cline { 2 - 5 } Process & $\begin{array}{l}\text { Vacuum } \\
\text { filtration }\end{array}$ & Freeze-drying & $\begin{array}{l}\text { Solvent exchange } \\
\text { and freeze-drying }\end{array}$ & $\begin{array}{l}\text { Supercritical } \\
\text { drying }\end{array}$ \\
\hline $\begin{array}{l}\text { Density } \\
\left(\mathrm{mg} . \mathrm{cm}^{-3}\right)\end{array}$ & 1374 & 10.2 & 16.4 & 24.3 \\
$\begin{array}{l}\text { Specific surface } \\
\text { area }\left(\mathrm{m}^{2} \cdot \mathrm{g}^{-1}\right)\end{array}$ & $\mathrm{n} / \mathrm{a}$ & $25 \pm 2$ & $97 \pm 4$ & $160 \pm 9$ \\
$\begin{array}{l}\text { Pore size from } \\
\text { SEM images } \\
(\mu \mathrm{m}) \text { n/a }\end{array}$ & $18 \pm 14$ & $18 \pm 10$ & $9 \pm 5$
\end{tabular}


Porous CNF structures with increasing specific surface areas were therefore obtained from the same CNF raw materials. Their high porosity and tunable specific surface areas properties are attractive for the supercritical impregnation of thymol and to understand the influence of the structure. These materials were thus impregnated with thymol in supercritical conditions at relatively low pressure and temperature conditions of 100 bars and $40^{\circ} \mathrm{C}$, respectively. The supercritical conditions were maintained during 1 hour. During this period, thymol fully dissolves in $\mathrm{scCO}_{2}$ and comes in contact with the dense (nanopapers) and porous (cryogels, aerogels) $\mathrm{CNF}$ structures. At the end of the process, the recovered materials were free of any solvent and remained structurally intact. When the impregnated structures were manipulated, a pleasant odor was noticed revealing the presence of thymol. To avoid evaporation of thymol from the structures, the samples were kept in sealed containers and stored at low temperatures. It is worth noting that a final dynamic step (during which the valves are open and there is a flow of $\mathrm{CO}_{2}$ ) and a depressurization step act as a washing process that removes the thymol that is not strongly adsorbed onto the CNF structures.

Scanning electron microscopy images of the impregnated materials are shown in Figure 1. Comparisons with the non-functionalized materials (i.e. before impregnation) unambiguously show that the impregnation step had no impact on the samples morphology that was kept intact. 

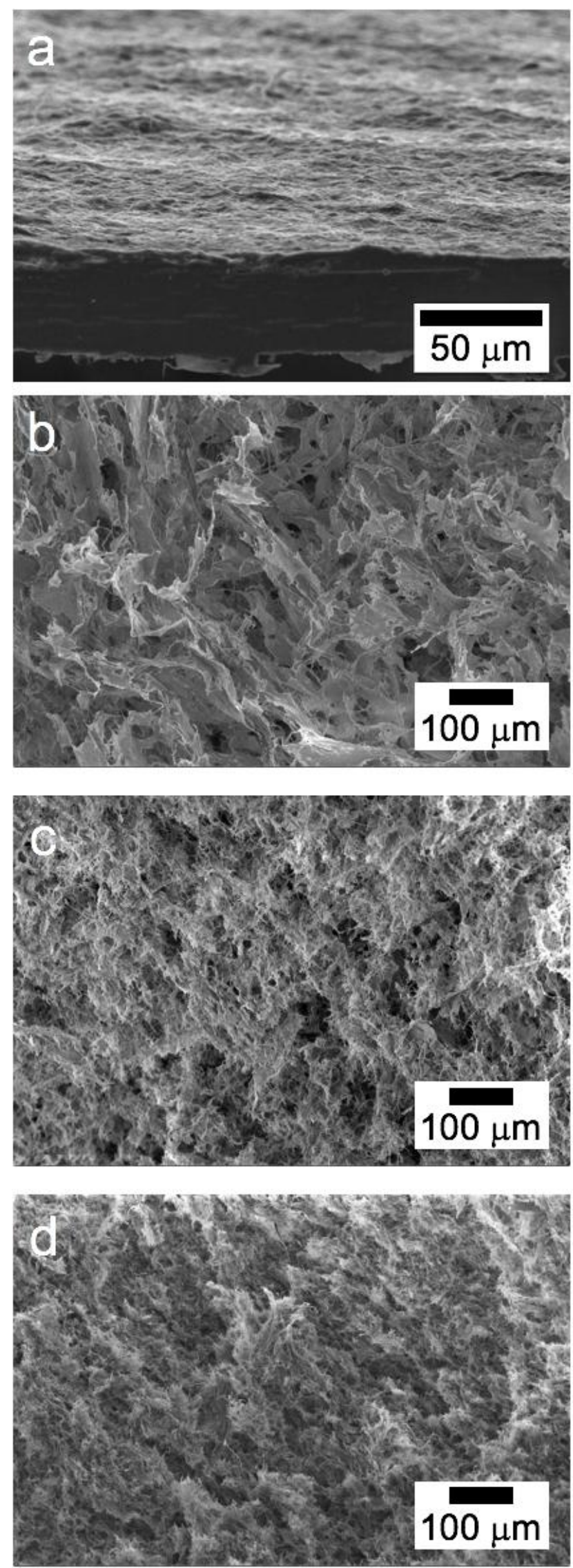
Figure 1. Scanning electron microscopy images of the thymo-impregnated CNF nanopaper (a), CGw cryogel (b), CGtBuOH cryogel (c) and aerogel (d).

\section{Quantification of supercritical impregnation of thymol}

In order to investigate whether the $\mathrm{scCO}_{2}$ had reached inside the $\mathrm{CNF}$ structures and whether thymol had been adsorbed inside the porous structures, a fluorescence analysis of the section of cryogels and aerogels was performed. The fluorescence intensity is given in arbitrary units and is usually tuned by the gain but here comparisons are possible since the same PMT gain was applied for each sample. Thin and homogeneous slices were cut in the center of the materials and the fluorescence intensity was monitored as depicted in Figure2a. The neat structures exhibit low intrinsic fluorescence that remains at least 5 times lower than the fluorescence intensity of impregnated structures. This first result confirms the loading of thymol inside the CNF materials. 

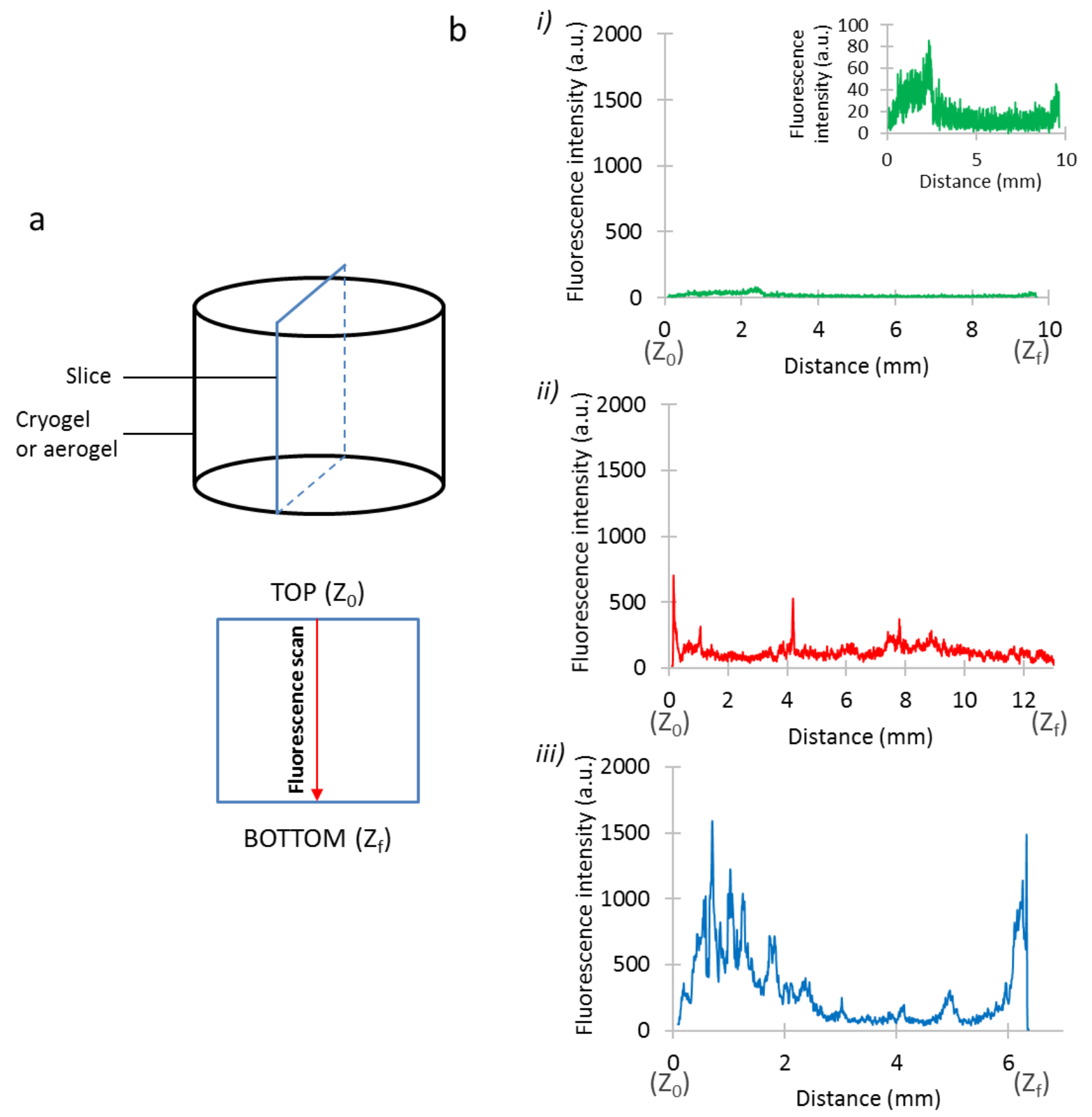

Figure 2. (a) Schematic representation of the slice collected from the cryogel or aerogels and the direction of the fluorescence scan throughout the slice. (b) Fluorescence intensity (arbitrary unit) throughout the thymol-impregnated cryogel $\mathrm{CGw}$, with zoomed-in graph in insert (i), $\mathrm{CGtBuOH}$ (ii) and aerogel (iii) slices.

The results of fluorescence intensity inside the cryogels and aerogels are presented in Figure2b. Inside $\mathrm{CGw}$, very low but homogeneous fluorescence was detected. When 
impregnation was performed in $\mathrm{CGtBuOH}$, a higher fluorescence intensity was measured and its distribution was less homogeneous. However, thymol has clearly penetrated the center of the cryogel, as both the center and the edges yield fluorescence. The highest fluorescence intensity was observed for aerogels. The fluorescence intensity is heterogeneously distributed throughout the slice, revealing a nonuniform penetration of thymol inside this type of porous material. This result was unexpected as aerogels are obtained from supercritical drying that produces structures with the most open and interconnected porosity. ${ }^{39}$ It appears that thymol is present in higher amounts on the edges than in the aerogel center. This could be due to non-visible differences, such as different specific surface area values between the edges and the center of the aerogels. High amounts of thymol do not infiltrate further than $2.5 \mathrm{~mm}$ inside the aerogel. After this distance the fluorescence intensity decreases down to the level measured in $\mathrm{CGtBuOH}$, indicating that thymol can penetrate to the aerogel center but tends to accumulate on the edges only. Both the top and bottom parts are scanned and show the presence of thymol, yet the impregnation is more efficient from the top than from the bottom of the aerogel as expressed by a higher fluorescence intensity in the top part of the aerogel. The fact that these materials are placed on an aluminum holder does not prevent impregnation at the bottom of the structure.

By plotting the average fluorescence intensity versus the specific surface area of the materials (Figure 3), a clear correlation is observed between the specific surface area of the porous material and the fluorescence intensity. The higher the specific surface area, the higher the fluorescence intensity and therefore the higher the amount of loaded thymol. 


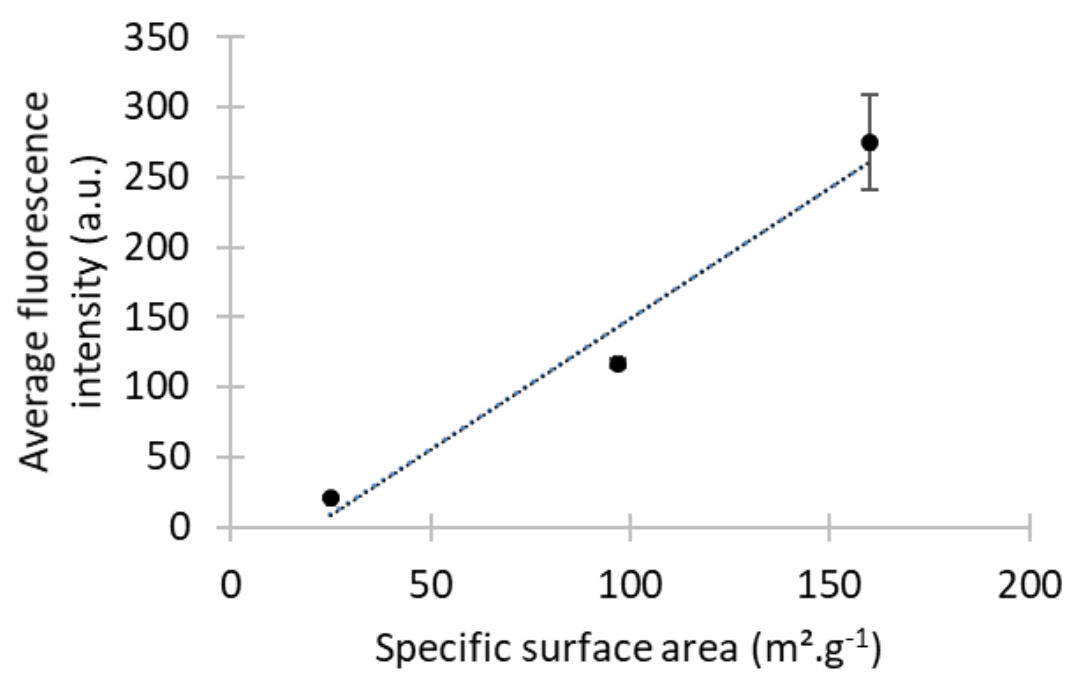

Figure 3. Average fluorescence intensity as a function of the specific surface area of the CNFbased material. The dotted line is a linear fit.

In this study, only three specific surface areas are taken into consideration, therefore it is difficult to unambiguously conclude whether the increase is linear or not. Yet, as the specific surface area increases, more CNF surface is available for the adsorption of thymol. This adsorption is considered to be mainly attributed to hydrogen bonding, as shown by Turki et al (2018). ${ }^{40}$ Similarly, Lombardo et al. have recently reported that the specific surface area was the most important parameter determining the amount of poorly-soluble drug sorbed onto $\mathrm{CNFs}^{34}$ This technique therefore confirms the presence of thymol and proves the influence of the specific surface area but it cannot provide quantification of the impregnation. In order to quantify the amount of thymol, impregnated structures were investigated with solid-state ${ }^{13} \mathrm{C}$ NMR (Figure 4). 


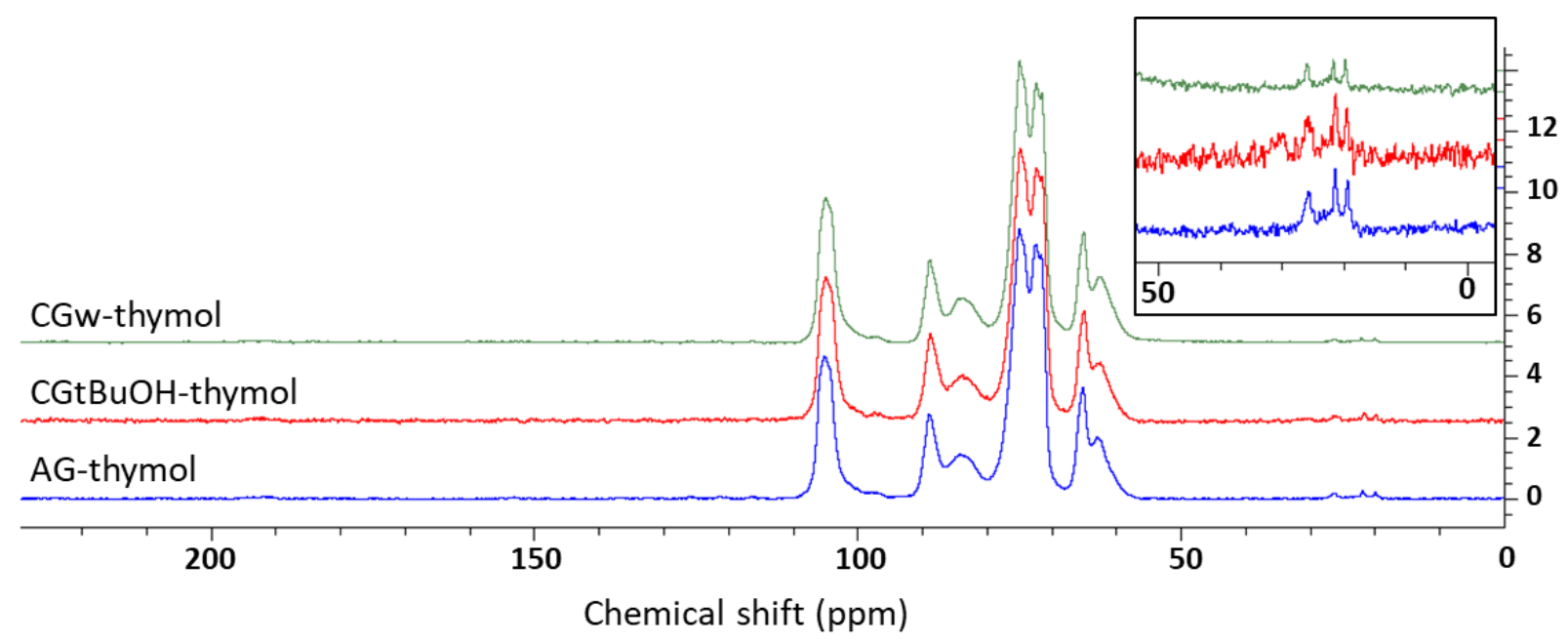

Figure 4. CP-MAS ${ }^{13} \mathrm{C}$ NMR spectra of thymol-impregnated $\mathrm{CGw}, \mathrm{CGtBuOH}$ and $\mathrm{AG}$.

First, a similar cellulose crystallinity (47 to $49 \%$ ), measured from carbon 4 signal between 80 to $93 \mathrm{ppm}$, is obtained for the three structures before and after functionalization in $\mathrm{scCO}_{2}$. In addition to the peaks corresponding to the carbons of cellulose, three new peaks emerge between 20 and $30 \mathrm{ppm}$, corresponding to the four aliphatic carbons of thymol. Aromatic carbons were expected between 110 and $160 \mathrm{ppm}$, however they cannot be seen in the spectra due to low signal to noise ratio. By integrating the carbons of cellulose and the aliphatic carbons of thymol, a molar ratio of impregnated thymol was calculated. Values of $0.8,1.4,1.9$ mol. \% were measured for $\mathrm{CGw}, \mathrm{CGtBuOH}$ and $\mathrm{AG}$, respectively. It has been reported that supercritical impregnation of PLA/PLGA materials with thymol yielded up to $6.62 \%$ of thymol. ${ }^{33}$ Supercritical impregnation of chitosan gels and cellulose acetate matrices supplied thymol ratios as high as $4.6 \%{ }^{30}$ and 72.26 , respectively. ${ }^{41}$ The results of NMR analysis show that relatively low amounts of thymol are impregnated inside CNF structures and that their preparation process and their specific surface area have an effect on the impregnation efficiency. As the specific surface area increases, the amount of impregnated thymol increases. These values are in agreement with the results of fluorescence intensity. However, this technique is not very accurate for such amounts of thymol 
and additional measurements using high sensitivity gas chromatography (GC) analysis coupled with mass spectroscopy (MS) were performed. Thymol is indeed highly volatile, therefore thermo-desorption at adequate temperature is expected to remove all thymol from the cryogels and aerogels.

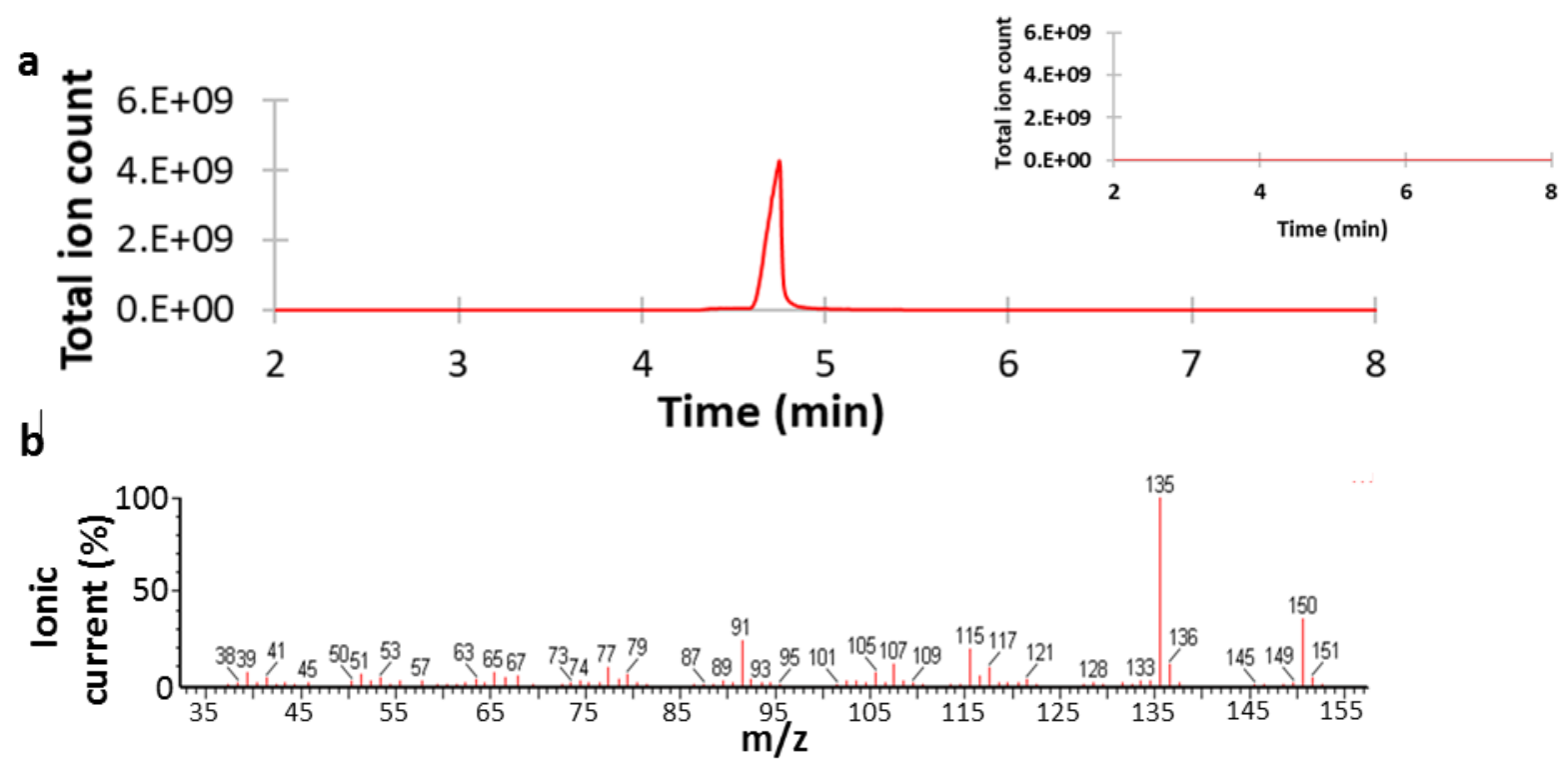

C

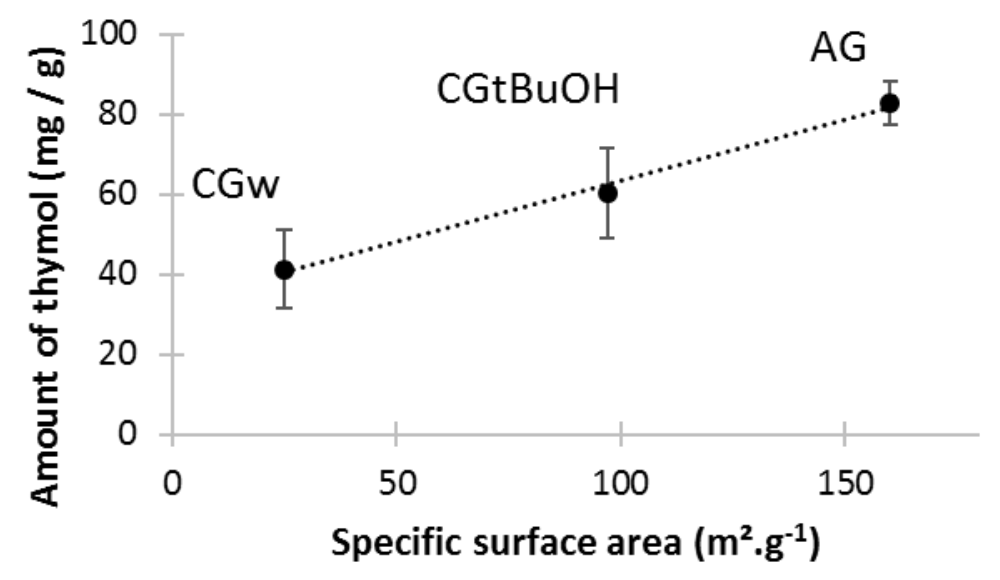

Figure 5. TD-GC-MS results of impregnated aerogel: gas-chromatogram after one thermodesorption and after two thermos-desorption in the insert (a), mass spectrum of the peak corresponding to thymol (b) and the amount of detected thymol as a function of the specific surface area of the CNF structure (c). The dotted line is a linear fit to the data. 
For the three porous structures, TD-GC-MS results exhibited a clear peak at $4.7 \mathrm{~min}$ as illustrated in Figure5a and Supporting Information Figure S2. The compound corresponding to this peak was analyzed through mass spectroscopy and it was confirmed to be thymol. No significant contamination of the samples was observed (Figure 5b). After the first thermodesorption, a second one was performed and the amount of thymol detected was lower than $0.5 \%$ of the amount desorbed the first time (Figure5a, insert). This illustrates the efficiency of the initial thermo-desorption at $180^{\circ} \mathrm{C}$. It also proves that the amount of thymol detected by GC stands for the amount adsorbed onto cellulose. Once again, the amount of detected thymol was plotted as a function of the specific surface area (Figure 5c). These amounts increase from 41 $\mathrm{mg} \cdot \mathrm{g}^{-1}$ for $\mathrm{CGw}$ to $60 \mathrm{mg} \cdot \mathrm{g}^{-1}$ for $\mathrm{CGtBuOH}$ and $83 \mathrm{mg} \cdot \mathrm{g}^{-1}$ for $\mathrm{AG}$. This trend is similar to the ones previously plotted thanks to fluorescence and NMR analyses: the larger the specific surface area, the more thymol is present inside the structures. This result quantitatively confirms that thymol impregnation is dependent on the CNF structures and specific surface area. Moreover, the strong correlation between the amount of thymol and the specific surface area indicates that thymol is adsorbed onto the CNF surfaces and not only trapped inside the porous structure.

\section{Thymol release analysis}

In vitro drug release was performed in PBS and the results are presented in Figure 6a. The releasing profiles indicate a clear burst release of thymol when the impregnated materials were immersed in PBS. After 40 min of release, a plateau was reached for AG. Regarding CGw and $\mathrm{CGtBuOH}$ structures, release turned out to be sustained for slightly longer times and the plateau was reached after 60 and 100 min, respectively. The release kinetics of AG is in good correlation with the impregnation profiles measured with fluorescence scanning: more thymol was detected on the outer layer of the aerogel, explaining the more pronounced burst release effect observed for this structure. 
The highest amount of thymol was released from AG with a value of $56 \pm 4 \mathrm{mg} \cdot \mathrm{g}^{-1}$. Lower amounts of $44 \pm 2$ and $22 \pm 1 \mathrm{mg} \cdot \mathrm{g}^{-1}$ were released from CGtBuOH and CGw, respectively.

These values are higher than the amount of thymol released from supercritical impregnated PLGA foams ${ }^{33}$ with up to $8.8 \mathrm{mg}$ of thymol released per gram of foam in PBS and Ncarboxybutyl chitosan membranes ${ }^{42}$ with up to $20 \mathrm{mg} / \mathrm{g}$ of thymol released. Higher amounts were released from cellulose acetate ${ }^{41}(170 \mathrm{mg} / \mathrm{g}$ of thymol released). In the latter case, the impregnation was performed during 32 hours.

Nanopapers have also been impregnated for comparison and almost no thymol was detected in the releasing media, with a value as low as $0.3 \pm 0.03 \mathrm{mg} \cdot \mathrm{g}^{-1}$. The amount of thymol is underestimated compared to TD-GC results, but remains in the same order of magnitude, proving that a fraction of thymol is strongly adsorbed. This indicates that not all thymol is released in PBS due to strong adsorption interactions, even though the sink conditions are reached at all time. This is additional evidence that the thymol is adsorbed onto the CNF structures and not only trapped inside the pores of the structure.

Once again, a similar trend emerges from the release kinetics (Figure 6b): the larger the specific surface area, the more thymol is released. The amount of thymol released from the CNF nanopapers is much lower than the value expected from the linear regression. This behavior observed for a high-density material reveals that not only the specific surface area plays a role in the impregnation efficiency but also the porous organization: both of them contribute to improve supercritical impregnation. By tuning the specific surface area and the porosity, the amount of thymol impregnated and released from the CNF structures can be controlled. 

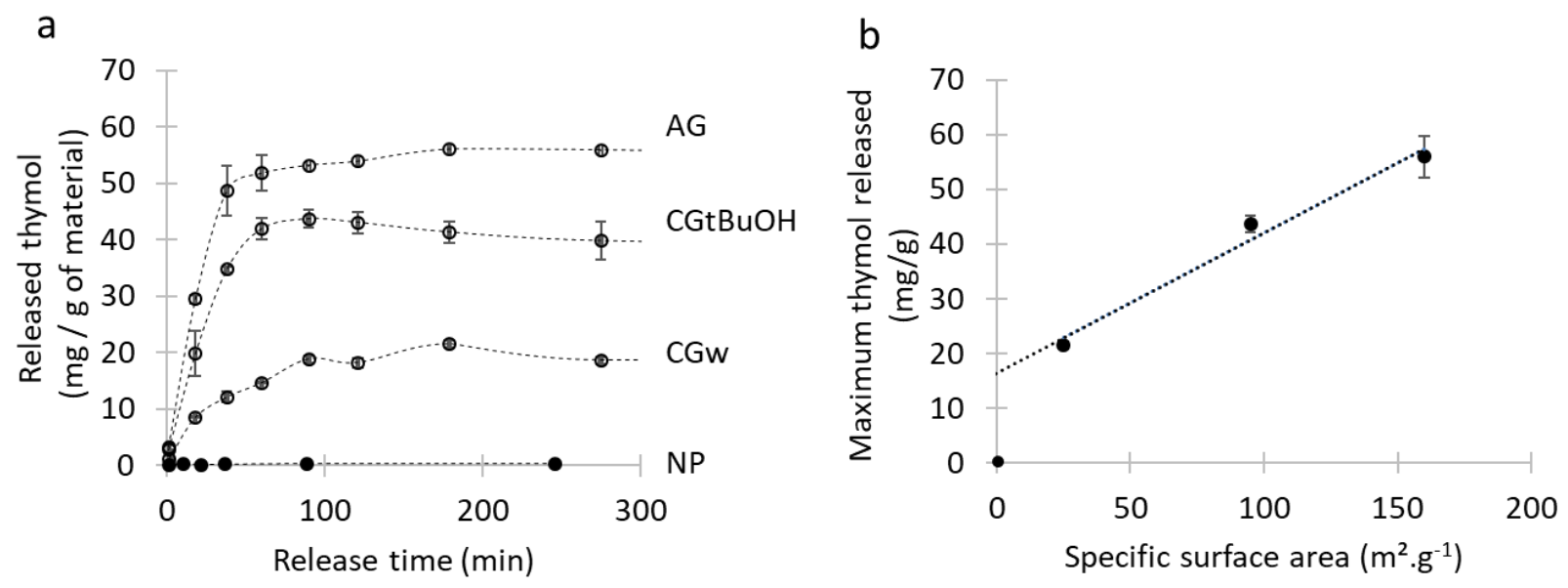

Figure 6. Kinetics of thymol release in PBS (a) and maximum released thymol as a function of the specific surface area (b).

\section{Antimicrobial properties assessment}

The antimicrobial properties of the four functionalized structures were investigated towards Gram-negative bacteria (E. coli), Gram-positive bacteria (S. epidermidis) and a yeast $(C$. albicans). Thymol was adsorbed and not covalently bound to the CNF materials, therefore their antimicrobial activity was assessed in conditions analogous to the disk diffusion test, on solid agar plates. As thymol diffuses through the agar medium, the growth of microorganisms is inhibited over a circular zone around the material to be tested. From the dimensions of this zone, the inhibition diameter is calculated and the wider this diameter is, the more effective and concentrated is the antimicrobial agent. The neat materials ( $\mathrm{NP}, \mathrm{CGw}, \mathrm{CGtBuOH}$ and $\mathrm{AG}$ ) were tested towards the three reference microorganisms and no inhibition zone was observed, as expected, as they do not have intrinsic antimicrobial properties. The inhibition diameters of the impregnated materials are summarized in Figure 7. No inhibition zone was visible when impregnated nanopapers were tested. This result was expected as previous results have shown that very low amounts of thymol are impregnated on this $2 \mathrm{D}$ closed structure. Growth inhibition 
was observed for impregnated $\mathrm{CGw}$ against the three microorganisms, mainly underneath the cryogel only and is expressed by inhibition diameters close to the size of the standardized structure diameters $(6.2$ to $6.4 \mathrm{~mm})$. Clear inhibition zones were observed for impregnated $\mathrm{CGtBuOH}$, and their size varied from one microorganism to the other. This indicates that sufficient amount of thymol was released and has diffused in the agar to reach the minimum inhibitory concentration values. The MIC for thymol has been determined for $E$. coli, $S$. epidermidis and $C$. albicans through broth dilution tests and the values are 250, 500 and $300 \mu \mathrm{g} \cdot \mathrm{mL}^{-1}$, respectively. To provide a comparison with antibiotics, these values are, in the case of $E$. coli, thirty times as high as the highest MIC of antibiotics $\left(8 \mu \mathrm{g} \cdot \mathrm{mL}^{-1}\right.$ typically). ${ }^{43}$ E. coli was the most sensitive microorganism to thymol and a large inhibition diameter of $10.1 \mathrm{~mm}$ was reached with $\mathrm{CGtBuOH}$, while $S$. epidermidis and $C$. albicans are less sensitive and exhibited smaller inhibition diameters of 7.3 and $7.6 \mathrm{~mm}$, respectively. Thymol-impregnated AG gave rise to the widest inhibition diameters for the three microorganisms. As expected, a larger inhibition diameter was noticed against E. coli $(10.4 \mathrm{~mm})$, whereas $S$. epidermidis and $C$. albicans exhibited 8.4 and $8.5 \mathrm{~mm}$ inhibition diameters, respectively. Besides the amount of released thymol, the diffusion of this hydrophobic antimicrobial agent in the agar appears to become the limiting factor for increased inhibition diameters: $\mathrm{CGtBuOH}$ and $\mathrm{AG}$ exhibit similar inhibition diameters against E. coli, while previous results have proved that more thymol is impregnated into AG and released. 


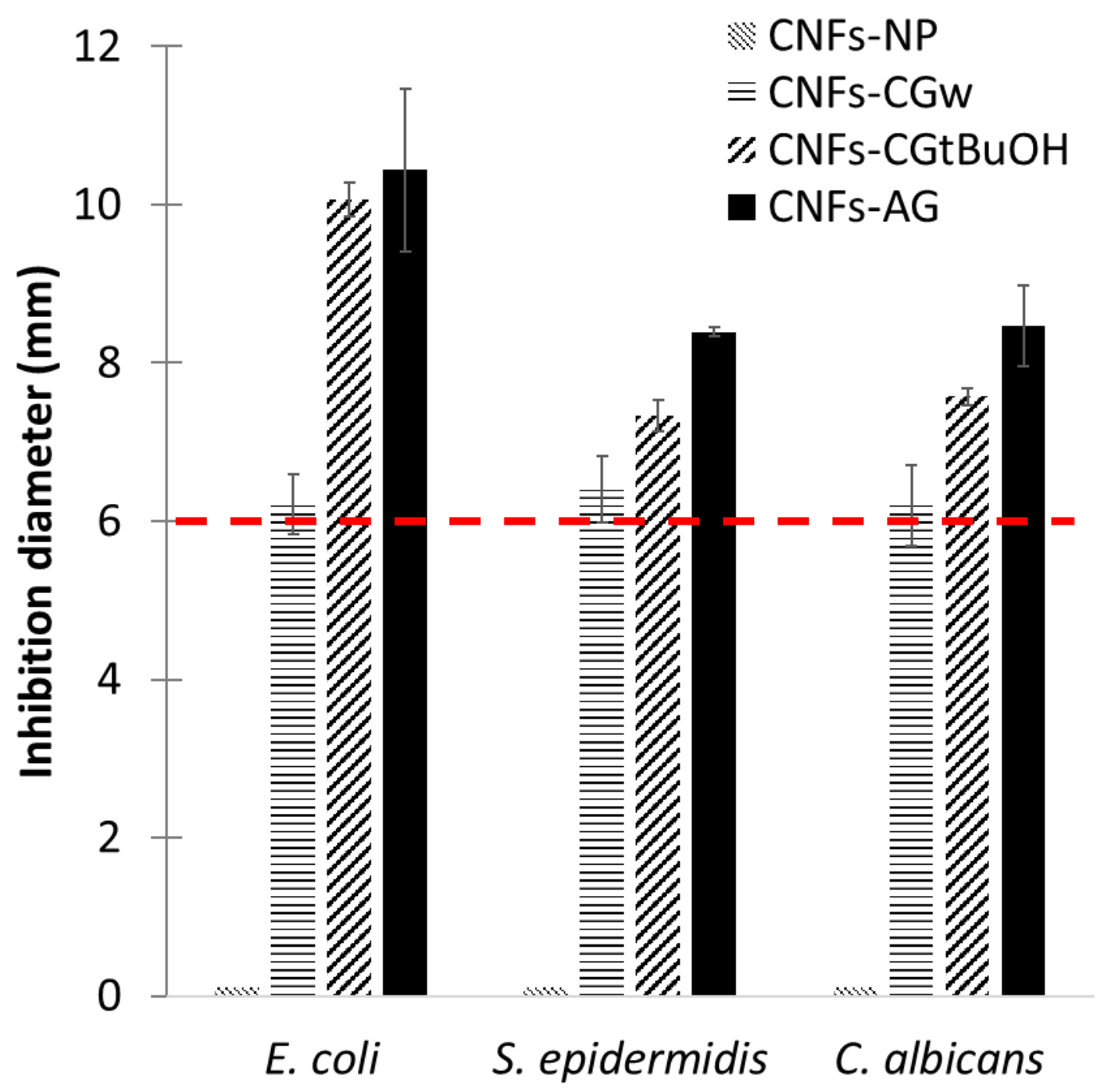

Figure 7. Inhibition diameters for E. coli, S. epidermidis and C. albicans measured with NP, $\mathrm{CGw}, \mathrm{CGtBuOH}$ and $\mathrm{AG}$ impregnated with thymol. The red dotted line corresponds to the normalized diameter of the structures.

The inhibition diameters reported in the presence of impregnated $\mathrm{CGtBuOH}$ and $\mathrm{AG}$ are similar to the ones reported by Jemaa et al. (2018) ${ }^{44}$ who reported considerable activity of free and encapsulated thyme essential oil against five microorganisms including E. coli for which inhibition diameters from 8.87 to $13.3 \mathrm{~mm}$ were reported. These results are very promising and 
confirm that supercritical impregnation of active molecules onto nanocellulose 3D structures can be an interesting solution for the design of active medical devices such as wound dressings.

\section{Cytotoxicity of thymol-impregnated CNF-based structures}

The cytotoxicity of thymol and thymol-impregnated structures was investigated with fibroblasts and results are presented in Figure 8. According to the ISO 10993-5-2009, a material is considered nontoxic for values of cell viability higher than $70 \%$.
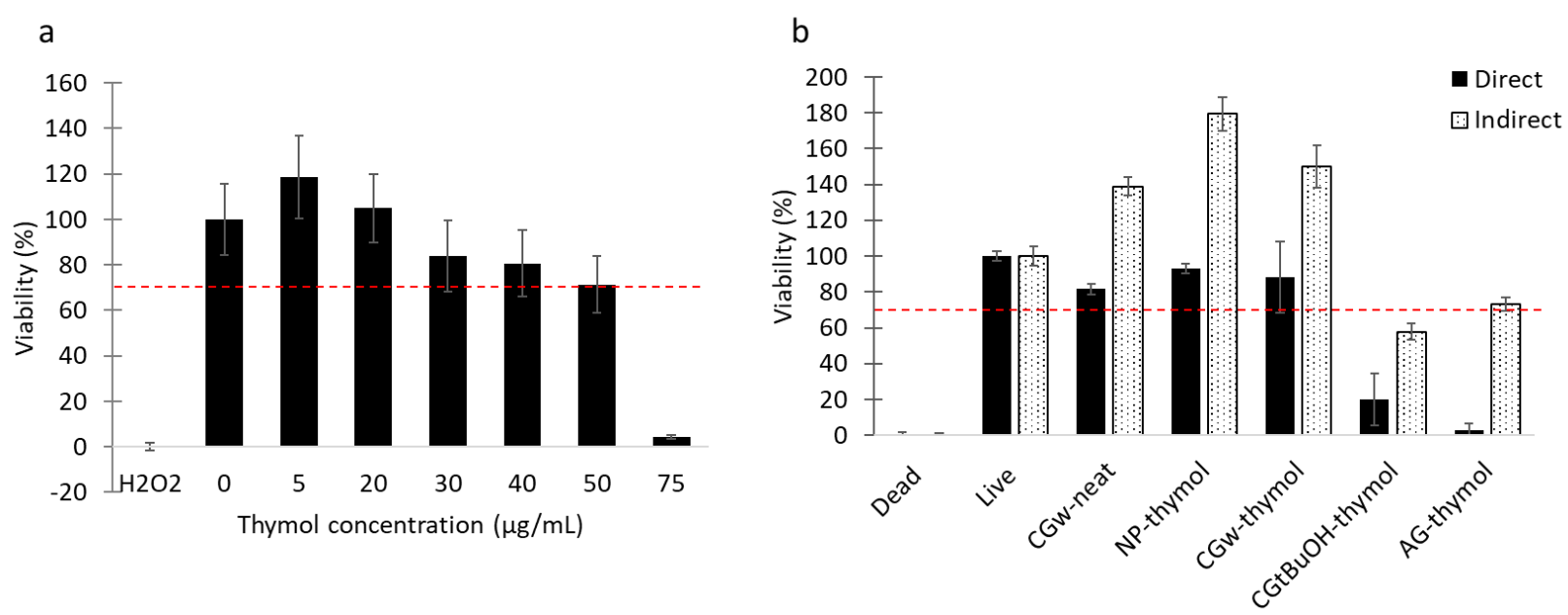

Figure 8. Cell viability in presence of thymol (a) and of neat CNF cryogels and thymolimpregnated structures (b) Red dotted line indicates the limit of cytotoxicity.

The thymol molecule exhibits a low cytotoxicity compared to synthetic antibiotics, ${ }^{45}$ with $70 \%$ cell viability up to $50 \mu \mathrm{g} \cdot \mathrm{mL}^{-1}$ of thymol as illustrated in Figure 8a. The neat CNF materials do not induce cytotoxicity as illustrated by cell viability in contact with neat $\mathrm{CGw}$ higher than $70 \%$ and exhibit enhanced cell viability in the indirect protocol (Figure 8b). Such behavior has been reported by Hua et al. ${ }^{46}$ and Rashad et al. ${ }^{47}$ for cells cultured in green algae nanocellulose extracts and wood CNF extracts, respectively. The cell viability is thought to be affected by the release of glucose from CNF materials which boosts the cell proliferation by promoting adhesion. $^{48}$ 
Thymol-impregnated NP and CGw exhibit good cell viability with values of 93 and $88 \%$, respectively, for the direct protocol and an increase in cell viability to 179 and $150 \%$, respectively, was observed for the indirect conditions. A review of the effects of thymol on the wound healing process compiles 10 studies that have shown the role of thymol to enhance the reepithelization of wound injuries and the stimulatory effect of low concentrations of thymol on fibroblasts. ${ }^{4}$ However, thymol-impregnated $\mathrm{CGtBuOH}$ and $\mathrm{AG}$ exhibit cytotoxicity with strong decrease of cell viability in direct conditions. In indirect conditions, only thymol-impregnated $\mathrm{CGtBuOH}$ exhibits cytotoxicity with a value of cell viability of $58 \%$, while AG-thymol exhibit $73 \%$ cell viability after 24 hours, above the limit to consider a material non-cytotoxic. These results in direct conditions are consistent with the low amount of thymol impregnated in NP and CGw and higher amounts in $\mathrm{CGtBuOH}$ and $\mathrm{AG}$.

In the presence of CNF structures with high amounts of impregnated thymol there is a competition between the enhanced viability due to nanocellulose-materials and the decreased viability due to large amounts of thymol. Cells are introduced into a media where nanocellulose materials have released factors enhancing the growth (glucose), that is why an increase of cell viability is observed in the indirect conditions when comparing to the direct protocol. This mechanism is presumably slow. In the direct conditions, cells are introduced into a medium where thymol is rapidly released, while nanocellulose liberates more slowly factors enhancing the growth. That is why a lower viability emerged from these direct conditions.

Impregnated $\mathrm{CGtBuOH}$ and $\mathrm{AG}$ exhibited antimicrobial activity, while NP and CGw exhibited no or low antibacterial activity. In vitro experiments show that in order to yield antimicrobial activity, high amounts of thymol must be impregnated, leading to direct cytotoxicity in the case of $\mathrm{CGtBuOH}$ and AG. These results are consistent with Pivetta et al. study, ${ }^{49}$ where they have shown enhanced cell viability of keratinocytes at low concentrations of thymol and a reduced cell 
viability at high concentrations $(200 \mu \mathrm{m})$. These results are promising and further in vivo investigations would attest on the innocuousness and possible use of the designed materials as wound dressings.

\section{CONCLUSION}

Four types of cellulose nanofibril structures were impregnated with a natural active molecule, here thymol, in supercritical carbon dioxide as a green alternative to common solvent. The effect of the morphology and the specific surface area of the CNF materials on the impregnation efficiency was investigated. Fluorescence analysis, ${ }^{13} \mathrm{C}$ solid-state NMR, gas-chromatography confirmed the successful impregnation of thymol inside cryogels and aerogels. The different characterizations led to the conclusion that higher amounts of thymol are sorbed when specific surface area increases. This result opens up the way for the supercritical impregnation of a wide range of various phenolic compounds with different activities, such as gallic acid, eugenol or linalool.

The antimicrobial activity of the impregnated CNF structures was assessed in vitro. Functionalized $\mathrm{CGtBuOH}$ and $\mathrm{AG}$, which incorporated the highest amount of thymol, exhibit good antimicrobial activity against two bacteria and one yeast as shown by the large inhibition diameters around these materials. On the other hand, NP and CGw exhibited no or low antimicrobial activity but low impregnation yields resulted in structures that enhanced the cell viability. These results are very promising to design antimicrobial bio-based and biocompatible medical devices using supercritical conditions. Moreover, this strategy has proved that it was possible to tune the amount of thymol loaded and the bioactivity by controlling the specific surface area of the material and results in precise control over the properties of the materials, such as enhanced cell viability or antimicrobial activity. In order to achieve long-term antibacterial 
activity, this strategy can be combined with covalent grafting of antibiotics, such as vancomycin. The covalent bond would preferably be a bond that can be hydrolyzed by enzyme action, such as esterase.

\section{ASSOCIATED CONTENT}

\section{Supporting Information}

Transmission electron microscopy image and photograph of CNF suspension; Gas chromatogram of cryogel $\mathrm{CGtBuOH}$ and $\mathrm{CGw}$ after one thermo-desorption.

\section{AUTHOR INFORMATION}

\section{Corresponding Author}

*e-mail: guillaume.nonglaton@cea.fr

\section{Author Contributions}

The manuscript was written through contributions of all authors. All authors have given approval to the final version of the manuscript.

\section{ACKNOWLEDGEMENTS}

This work was supported by a grant from Labex ARCANE (ANR-11-LABX-0003-01) and CBH-EUR-GS (ANR-17-EURE-0003) and supported by the "Investissement d'Avenir" program Glyco@Alps (ANR-15-IDEX-02). This research was made possible thanks to the facilities of the TekLiCell platform funded by the Région Rhône-Alpes (ERDF: European regional development fund). LGP2 is part of the LabEx Tec 21 (Investissements d'Avenir-Grant Agreement No. ANR-11- LABX-0030) and of PolyNat Carnot Institute (Investissements d'Avenir-Grant Agreement No. ANR-16-CARN-0025-01). The authors acknowledge the Borregaard company 
for providing CNF materials and the NanoBio- ICMG chemistry platform (ICMG FR 2607) for granting access to the electron microscopy facility. The authors thank Jean-Luc Putaux, Christine Lancelon-Pin and Bertine Khelifi for the microscopy images.

\section{REFERENCES}

(1) Jones, V.; Grey, J. E.; Harding, K. G. Wound Dressings. BMJ 2006, 332 (7544), 777-780. https://doi.org/10.1136/bmj.332.7544.777.

(2) Simões, D.; Miguel, S. P.; Ribeiro, M. P.; Coutinho, P.; Mendonça, A. G.; Correia, I. J. Recent Advances on Antimicrobial Wound Dressing: A Review. European Journal of Pharmaceutics and Biopharmaceutics 2018, 127, 130-141. https://doi.org/10.1016/j.ejpb.2018.02.022.

(3) Pérez-Recalde, M.; Ruiz Arias, I. E.; Hermida, É. B. Could Essential Oils Enhance Biopolymers Performance for Wound Healing? A Systematic Review. Phytomedicine 2018, 38, 57-65. https://doi.org/10.1016/j.phymed.2017.09.024.

(4) Costa, M. F.; Durço, A. O.; Rabelo, T. K.; Barreto, R. de S. S.; Guimarães, A. G. Effects of Carvacrol, Thymol and Essential Oils Containing Such Monoterpenes on Wound Healing: A Systematic Review. Journal of Pharmacy and Pharmacology 2019, 71 (2), 141-155. https://doi.org/10.1111/jphp.13054.

(5) Tisserand, R.; Young, R. Essential Oil Safety - E-Book: A Guide for Health Care Professionals; Elsevier Health Sciences, 2013.

(6) Lambert, R. j. w.; Skandamis, P. n.; Coote, P. j.; Nychas, G.-J. e. A Study of the Minimum Inhibitory Concentration and Mode of Action of Oregano Essential Oil, Thymol and Carvacrol. Journal of Applied Microbiology 2001, 91 (3), 453-462. https://doi.org/10.1046/j.1365-2672.2001.01428.x.

(7) Nagoor Meeran, M. F.; Javed, H.; Al Taee, H.; Azimullah, S.; Ojha, S. K. Pharmacological Properties and Molecular Mechanisms of Thymol: Prospects for Its Therapeutic Potential and Pharmaceutical Development. Front. Pharmacol. 2017, 8. https://doi.org/10.3389/fphar.2017.00380.

(8) Marchese, A.; Orhan, I. E.; Daglia, M.; Barbieri, R.; Di Lorenzo, A.; Nabavi, S. F.; Gortzi, O.; Izadi, M.; Nabavi, S. M. Antibacterial and Antifungal Activities of Thymol: A Brief Review of the Literature. Food Chemistry 2016, 210, 402-414. https://doi.org/10.1016/j.foodchem.2016.04.111.

(9) Aeschbach, R.; Löliger, J.; Scott, B. C.; Murcia, A.; Butler, J.; Halliwell, B.; Aruoma, O. I. Antioxidant Actions of Thymol, Carvacrol, 6-Gingerol, Zingerone and Hydroxytyrosol. Food and Chemical Toxicology 1994, 32 (1), 31-36. https://doi.org/10.1016/02786915(84)90033-4.

(10) Riella, K. R.; Marinho, R. R.; Santos, J. S.; Pereira-Filho, R. N.; Cardoso, J. C.; Albuquerque-Junior, R. L. C.; Thomazzi, S. M. Anti-Inflammatory and Cicatrizing Activities of Thymol, a Monoterpene of the Essential Oil from Lippia Gracilis, in Rodents. Journal of Ethnopharmacology 2012, $143 \quad$ (2), 656-663. https://doi.org/10.1016/j.jep.2012.07.028. 
(11) Muñoz-Bonilla, A.; Echeverria, C.; Sonseca, Á.; Arrieta, M. P.; Fernández-García, M. BioBased Polymers with Antimicrobial Properties towards Sustainable Development. Materials 2019, 12 (4), 641. https://doi.org/10.3390/ma12040641.

(12) Muñoz-Bonilla, A.; Fernández-García, M. Polymeric Materials with Antimicrobial Activity. Progress in Polymer Science 2012, 37 (2), 281-339. https://doi.org/10.1016/j.progpolymsci.2011.08.005.

(13) Chen, J.; Wang, F.; Liu, Q.; Du, J. Antibacterial Polymeric Nanostructures for Biomedical Applications. Chem. Commun. 2014, 50 (93), 14482-14493. https://doi.org/10.1039/C4CC03001J.

(14) Jorfi, M.; Foster, E. J. Recent Advances in Nanocellulose for Biomedical Applications. Journal of Applied Polymer Science 2015, 132 (14), n/a-n/a. https://doi.org/10.1002/app.41719.

(15) Naseri-Nosar, M.; Ziora, Z. M. Wound Dressings from Naturally-Occurring Polymers: A Review on Homopolysaccharide-Based Composites. Carbohydrate Polymers 2018, 189, 379-398. https://doi.org/10.1016/j.carbpol.2018.02.003.

(16) Sahana, T. G.; Rekha, P. D. Biopolymers: Applications in Wound Healing and Skin Tissue Engineering. Molecular Biology Reports 2018, 45 (6), 2857-2867. https://doi.org/10.1007/s11033-018-4296-3.

(17) Basu, A.; Heitz, K.; Strømme, M.; Welch, K.; Ferraz, N. Ion-Crosslinked Wood-Derived Nanocellulose Hydrogels with Tunable Antibacterial Properties: Candidate Materials for Advanced Wound Care Applications. Carbohydrate Polymers 2018, 181, 345-350. https://doi.org/10.1016/j.carbpol.2017.10.085.

(18) Bacakova, L.; Pajorova, J.; Bacakova, M.; Skogberg, A.; Kallio, P.; Kolarova, K.; Svorcik, V. Versatile Application of Nanocellulose: From Industry to Skin Tissue Engineering and Wound Healing. Nanomaterials 2019, 9 (2), 164. https://doi.org/10.3390/nano9020164.

(19) Abitbol, T.; Rivkin, A.; Cao, Y.; Nevo, Y.; Abraham, E.; Ben-Shalom, T.; Lapidot, S.; Shoseyov, O. Nanocellulose, a Tiny Fiber with Huge Applications. Current Opinion in Biotechnology 2016, 39, 76-88. https://doi.org/10.1016/j.copbio.2016.01.002.

(20) Klemm, D.; Kramer, F.; Moritz, S.; Lindström, T.; Ankerfors, M.; Gray, D.; Dorris, A. Nanocelluloses: A New Family of Nature-Based Materials. Angewandte Chemie International Edition 2011, 50 (24), 5438-5466. https://doi.org/10.1002/anie.201001273.

(21) Lavoine, N.; Bergström, L. Nanocellulose-Based Foams and Aerogels: Processing, Properties, and Applications. Journal of Materials Chemistry A 2017, 5 (31), 1610516117. https://doi.org/10.1039/C7TA02807E.

(22) De France, K. J.; Hoare, T.; Cranston, E. D. Review of Hydrogels and Aerogels Containing Nanocellulose. Chemistry of Materials 2017, 29 (11), 4609-4631. https://doi.org/10.1021/acs.chemmater.7b00531.

(23) Gupta, S.; Martoïa, F.; Orgéas, L.; Dumont, P. Ice-Templated Porous Nanocellulose-Based Materials: Current Progress and Opportunities for Materials Engineering. Applied Sciences 2018, 8 (12), 2463. https://doi.org/10.3390/app8122463.

(24) Benítez, A. J.; Walther, A. Cellulose Nanofibril Nanopapers and Bioinspired Nanocomposites: A Review to Understand the Mechanical Property Space. Journal of Materials Chemistry A 2017, 5 (31), 16003-16024. https://doi.org/10.1039/C7TA02006F.

(25) Parit, M.; Aksoy, B.; Jiang, Z. Towards Standardization of Laboratory Preparation Procedure for Uniform Cellulose Nanopapers. Cellulose 2018, 25 (5), 2915-2924. https://doi.org/10.1007/s10570-018-1759-6. 
(26) Altiok, D.; Altiok, E.; Tihminlioglu, F. Physical, Antibacterial and Antioxidant Properties of Chitosan Films Incorporated with Thyme Oil for Potential Wound Healing Applications. $J$ Mater Sci: Mater Med 2010, 21 (7), 2227-2236. https://doi.org/10.1007/s10856-010-4065-x.

(27) Jiji, S.; Udhayakumar, S.; Rose, C.; Muralidharan, C.; Kadirvelu, K. Thymol Enriched Bacterial Cellulose Hydrogel as Effective Material for Third Degree Burn Wound Repair. International Journal of Biological Macromolecules 2019, 122, 452-460. https://doi.org/10.1016/j.ijbiomac.2018.10.192.

(28) Kerrola, K. Literature Review: Isolation of Essential Oils and Flavor Compounds by Dense Carbon Dioxide. Food Reviews International 1995, 11 (4), 547-573. https://doi.org/10.1080/87559129509541061.

(29) Xu, L.; Zhan, X.; Zeng, Z.; Chen, R.; Li, H.; Xie, T.; Wang, S. Recent Advances on Supercritical Fluid Extraction of Essential Oils. African Journal of Pharmacy and Pharmacology 2011, 5 (9), 1196-1211. https://doi.org/10.5897/AJPP11.228.

(30) Terzić, I.; Ivanović, J.; Žižović, I.; Škorić, M. L.; Milosavljević, N.; Milašinović, N.; Krušić, M. K. A Novel Chitosan Gels: Supercritical CO2 Drying and Impregnation with Thymol. Polymer Engineering \& Science 2018, 58 (12), 2192-2199. https://doi.org/10.1002/pen.24834.

(31) da Silva, C. V.; Pereira, V. J.; Costa, G. M. N.; Cabral-Albuquerque, E. C. M.; Vieira de Melo, S. A. B.; de Sousa, H. C.; Dias, A. M. A.; Braga, M. E. M. Supercritical Solvent Impregnation/Deposition of Spilanthol-Enriched Extracts into a Commercial Collagen/Cellulose-Based Wound Dressing. The Journal of Supercritical Fluids 2018, 133, 503-511. https://doi.org/10.1016/j.supflu.2017.11.028.

(32) Milovanovic, S.; Stamenic, M.; Markovic, D.; Radetic, M.; Zizovic, I. Solubility of Thymol in Supercritical Carbon Dioxide and Its Impregnation on Cotton Gauze. The Journal of Supercritical Fluids 2013, 84, 173-181. https://doi.org/10.1016/j.supflu.2013.10.003.

(33) Milovanovic, S.; Markovic, D.; Mrakovic, A.; Kuska, R.; Zizovic, I.; Frerich, S.; Ivanovic, J. Supercritical CO2 - Assisted Production of PLA and PLGA Foams for Controlled Thymol Release. Materials Science and Engineering: C 2019, 99, 394-404. https://doi.org/10.1016/j.msec.2019.01.106.

(34) Zizovic, I.; Senerovic, L.; Moric, I.; Adamovic, T.; Jovanovic, M.; Krusic, M. K.; Misic, D.; Stojanovic, D.; Milovanovic, S. Utilization of Supercritical Carbon Dioxide in Fabrication of Cellulose Acetate Films with Anti-Biofilm Effects against Pseudomonas Aeruginosa and Staphylococcus Aureus. The Journal of Supercritical Fluids 2018, 140, 11-20. https://doi.org/10.1016/j.supflu.2018.05.025.

(35) Alvarado, N.; Romero, J.; Torres, A.; López de Dicastillo, C.; Rojas, A.; Galotto, M. J.; Guarda, A. Supercritical Impregnation of Thymol in Poly(Lactic Acid) Filled with Electrospun Poly(Vinyl Alcohol)-Cellulose Nanocrystals Nanofibers: Development an Active Food Packaging Material. Journal of Food Engineering 2018, 217, 1-10. https://doi.org/10.1016/j.jfoodeng.2017.08.008.

(36) Darpentigny, C.; Nonglaton, G.; Bras, J.; Jean, B. Highly Absorbent Cellulose Nanofibrils Aerogels Prepared by Supercritical Drying. Carbohydrate Polymers 2020, 229, 115560. https://doi.org/10.1016/j.carbpol.2019.115560.

(37) Brunauer, S.; Emmett, P. H.; Teller, E. Adsorption of Gases in Multimolecular Layers. Journal of the American Chemical Society 1938, 60 (2), 309-319. https://doi.org/10.1021/ja01269a023. 
(38) Bauer, A. W.; Kirby, W. M. M.; Sherris, J. C.; Turck, M. Antibiotic Susceptibility Testing by a Standardized Single Disk Method. American Journal of Clinical Pathology 1966, 45 (4_ts), 493-496. https://doi.org/10.1093/ajcp/45.4_ts.493.

(39) Sakai, K.; Kobayashi, Y.; Saito, T.; Isogai, A. Partitioned Airs at Microscale and Nanoscale: Thermal Diffusivity in Ultrahigh Porosity Solids of Nanocellulose. Scientific Reports 2016, 6 (1), 20434. https://doi.org/10.1038/srep20434.

(40) Turki, A.; El Oudiani, A.; Msahli, S.; Sakli, F. Investigation of OH Bond Energy for Chemically Treated Alfa Fibers. Carbohydrate Polymers 2018, 186, 226-235. https://doi.org/10.1016/j.carbpol.2018.01.030.

(41) Milovanovic, S.; Stamenic, M.; Markovic, D.; Ivanovic, J.; Zizovic, I. Supercritical Impregnation of Cellulose Acetate with Thymol. The Journal of Supercritical Fluids 2015, 97, 107-115. https://doi.org/10.1016/j.supflu.2014.11.011.

(42) Dias A. M.A.; $\square$; Seabra I. J, Braga M. M. E.; Gil M. H. , de Sousa H. C.; Dias A. M. A. Supercritical Solvent Impregnation of Natural Bioactive Compounds in N -Carboxybutyl Chitosan Membranes for the Development of Topical Wound Healing Applications. Journal of Controlled Release 2010, 148, 21-56.

(43) EUCAST. Recommandations of the European Committee on Antimicrobial Susceptibility Testing (accessed Oct 31, 2019).

(44) Jemaa, M. B.; Falleh, H.; Serairi, R.; Neves, M. A.; Snoussi, M.; Isoda, H.; Nakajima, M.; Ksouri, R. Nanoencapsulated Thymus Capitatus Essential Oil as Natural Preservative. Innovative Food Science \& Emerging Technologies 2018, 45, 92-97. https://doi.org/10.1016/j.ifset.2017.08.017.

(45) García-Salinas, S.; Elizondo-Castillo, H.; Arruebo, M.; Mendoza, G.; Irusta, S. Evaluation of the Antimicrobial Activity and Cytotoxicity of Different Components of Natural Origin Present in Essential Oils. Molecules 2018, 23 (6), 1399. https://doi.org/10.3390/molecules23061399.

(46) Hua, K.; Carlsson, D. O.; Ålander, E.; Lindström, T.; Strømme, M.; Mihranyan, A.; Ferraz, N. Translational Study between Structure and Biological Response of Nanocellulose from Wood and Green Algae. RSC Adv. 2014, 4 (6), 2892-2903. https://doi.org/10.1039/C3RA45553J.

(47) Rashad, A.; Mustafa, K.; Heggset, E. B.; Syverud, K. Cytocompatibility of Wood-Derived Cellulose Nanofibril Hydrogels with Different Surface Chemistry. Biomacromolecules 2017, 18 (4), 1238-1248. https://doi.org/10.1021/acs.biomac.6b01911.

(48) Stumpf, T. R.; Pértile, R. A. N.; Rambo, C. R.; Porto, L. M. Enriched Glucose and Dextrin Mannitol-Based Media Modulates Fibroblast Behavior on Bacterial Cellulose Membranes. Materials Science and Engineering: $C$ 2013, 33 (8), 4739-4745. https://doi.org/10.1016/j.msec.2013.07.035.

(49) Pivetta, T. P.; Simões, S.; Araújo, M. M.; Carvalho, T.; Arruda, C.; Marcato, P. D. Development of Nanoparticles from Natural Lipids for Topical Delivery of Thymol: Investigation of Its Anti-Inflammatory Properties. Colloids and Surfaces B: Biointerfaces 2018, 164, 281-290. https://doi.org/10.1016/j.colsurfb.2018.01.053. 


\section{Graphical abstract}

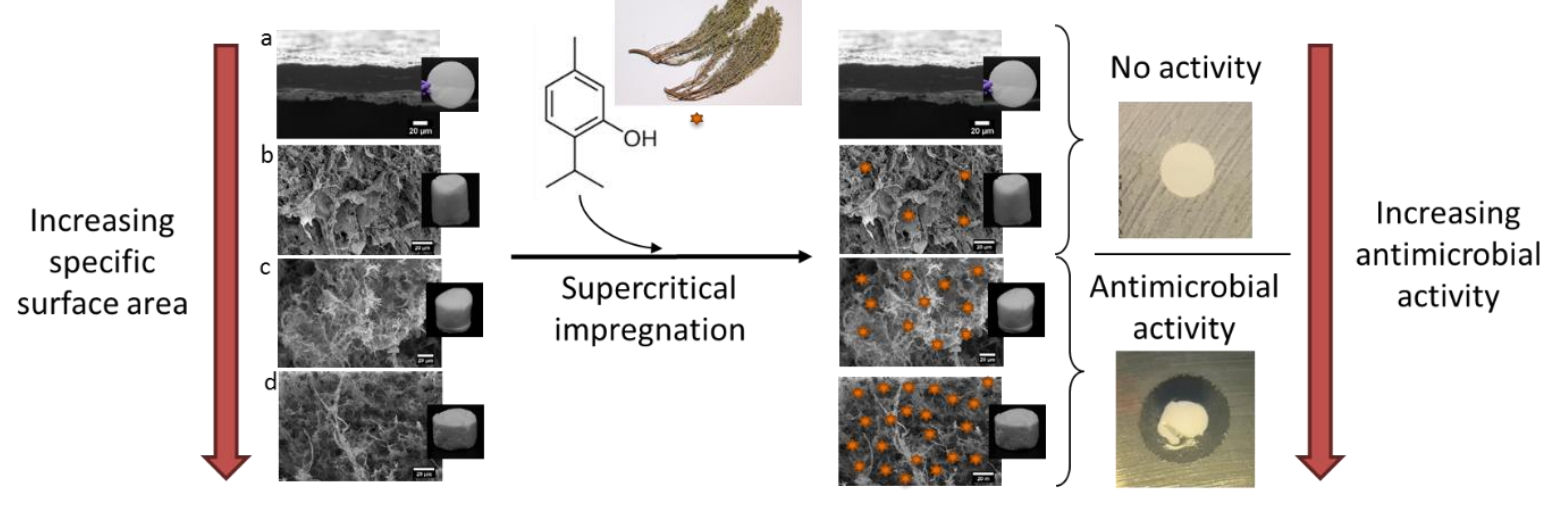

